\title{
ANÁliSE DE CUSTOS DA IMPLANTAÇÃo DE CULTIVOS DE EUCALIPTO EM ÁREAS ACIDENTADAS NO SUL DO ESPÍRITO SANTO
}

\author{
Flávio Cipriano de Assis do Carmo ${ }^{1}$, Nilton César Fiedler², Pompeu Paes Guimarães ${ }^{3}$, \\ Daniel Pena Pereira ${ }^{4}$, Wendel Sandro de Paula Andrade ${ }^{5}$
}

(recebido: 19 de abril de 2010; aceito: 30 de junho de 2011)

\begin{abstract}
RESUMO: Objetivou-se, por meio desta pesquisa, realizar uma análise de viabilidade econômica de cultivos de eucalipto em empreendimentos apoiados pelo fomento florestal, caracterizando os custos das operações de implantação, manutenção, colheita semimecanizada e transporte rodoviário de madeira em área com topografia acidentada no sul do Espírito Santo. Foi calculada a viabilidade econômica do projeto pelo valor presente líquido (VPL), taxa interna de retorno (TIR) e custo médio de produção (CMP), para os seguintes cenários de produtividade: 140,00;180,00;220,00; e 250,00 $\mathrm{m}^{3} / \mathrm{ha}$. De acordo com os resultados encontrados, o produtor teve um custo total de $\mathrm{R} \$ 10.381,24$; $\mathrm{R} \$ 11.306,59 ; \mathrm{R} \$ 12.115,79$; e $\mathrm{R} \$ 12.722,69 /$ ha para cada cenário analisado. $\mathrm{O}$ empreendimento não foi viável para a produtividade mínima de 140,00 $\mathrm{m}^{3} /$ ha (VPL de -R $\$ 127,14 / \mathrm{ha}$, TIR de $8,16 \%$ e CMP de $\mathrm{R} \$ 58,29 / \mathrm{m}^{3}$ ) e foi viável para as produtividades acima de $180,00 \mathrm{~m}^{3} / \mathrm{ha}$. O cenário de produtividade de $250,00 \mathrm{~m}^{3} / \mathrm{ha}$ apresentou os melhores indicadores: maior VPL (R $\$ 2.412,14 / \mathrm{ha})$, maior TIR (17,24\%) e menor CMP $\left(\mathrm{R} \$ 40,83 / \mathrm{m}^{3}\right)$.
\end{abstract}

Palavras-chave: Plantios florestais, fomento florestal, avaliação econômica de projetos.

\section{COSTS ANALYSIS OF EUCALYPTUS IMPLANTATION ON STEEP AREAS IN THE SOUTH OF THE ESPÍRITO SANTO STATE, BRAZIL}

\begin{abstract}
This research carried out a cost analysis of the subsidized timber production of eucalyptus in the activities of implementation, maintenance, partially mechanized harvesting and transport of timber on steep topography in the south of the Espirito Santo, Brazil. The economic viability of the project was calculated through the net present value (VPL), internal rate of return (TIR) and average cost of production (CMP) for the following productivities: 140.00; 180.00; $220.00 ;$ and $250.00 \mathrm{~m}^{3} \mathrm{ha}^{-1}$. According to these results, the producer had a total cost of 10381.24; 11306.59; 12115.79; and $R \$ 12722.69$ per hectare for each scenario. The project was not feasible for the minimum productivity of $140.00 \mathrm{~m}^{3} \mathrm{ha}^{-1}$ (VPL R\$ $127.14 \mathrm{ha}^{-1}$, TIR $8.16 \%$ and CMP $\left.R \$ 58.29 \mathrm{~m}^{-3}\right)$ and was feasible for yields of 180.00, 220.00, and $250.00 \mathrm{~m}^{3} \mathrm{ha}^{-1}$, being more attractive at productivity of $250.00 \mathrm{~m}^{3}$ $h \mathrm{a}^{-1}$ that presented the highest VPL $\left(R \$ 2412.14 \mathrm{ha}^{-1}\right)$, the highest TIR $(17.24 \%)$ and the lowest CMP $\left(R \$ 40.83 \mathrm{~m}^{-3}\right)$.
\end{abstract}

Key words: Forestry plantation, forestry program, economic evaluation, project analysis.

\section{INTRODUÇÃO}

Uma das funções atuais dos plantios florestais, segundo Silva et al. (2004), consiste em diminuir a pressão de demanda sobre as espécies nativas, muitas vezes com elevado risco de extinção.

Embora seja usual para empresas florestais analisar economicamente seus projetos, ainda existe escassez de estudos nesse sentido, inclusive nos programas de fomento florestal (REZENDE et al., 2006).
Em estabelecimentos participantes do programa de fomento florestal do Espírito Santo, o sistema de produção é pouco desenvolvido tecnologicamente e a mão-deobra utilizada é, em sua maioria, familiar, sendo que os equipamentos utilizados são os mesmos aplicados em outras atividades da propriedade, com algumas adaptações (SIQUEIRA et al., 2004).

Os projetos florestais caracterizam-se pelo elevado investimento inicial, longo tempo de maturação, retorno no longo prazo, elevados riscos de incêndios, ataques

\footnotetext{
${ }^{1}$ Engenheiro Florestal, Mestrando em Ciências Florestais - Departamento de Engenharia Florestal - Centro de Ciências Agrárias - Universidade Federal do Espírito Santo - Cx. P. 16 - 29500-000 - Alegre, ES - flaviocipriano@hotmail.com

${ }^{2}$ Engenheiro Florestal, Professor Dr. em Ciência Florestal - Departamento de Engenharia Florestal - Centro de Ciências Agrárias - Universidade Federal do Espírito Santo - Cx. P. 16 - 29500-000 - Alegre, ES - fiedler@pq.cnpq.br

${ }^{3}$ Engenheiro Florestal, Doutorando em Engenharia Florestal - Departamento de Engenharia Florestal - Centro de Ciências Agrárias - Universidade Federal do Espírito Santo - Cx. P. 16 - 29500-000 - Alegre, ES - pompeupaes@yahoo.com.br

${ }^{4}$ Engenheiro Agrônomo, Doutorando em Produção Vegetal - Departamento de Engenharia Florestal - Centro de Ciências Agrárias - Universidade Federal do Espírito Santo - Cx. P. 16 - 29500-000 - Alegre, ES - daniel@geraes.org

${ }^{5}$ Engenheiro Agrônomo, Professor Dr. em Economia Aplicada - Departamento de Engenharia Florestal - Centro de Ciências Agrárias - Universidade Federal do Espírito Santo - Av. Governador Lindemberg, 316 (NEDTEC) - 29550-000 - Jeronimo Monteiro, ES - wendelandrade@hotmail.com
}

Cerne, Lavras, v. 17, n. 4, p. 473-479, out./dez. 2011 
de pragas e doenças e variações nos preços da madeira. Além disso, o produtor florestal tem que tomar decisão de investimento, baseando-se no preço corrente do produto, uma vez que o preço futuro, em geral, é desconhecido (SOARES et al., 2007).

De acordo com Silva et al. (2004), as informações relativas aos custos de todas as etapas de implantação de um projeto são necessárias para a viabilização de recursos para a execução de cada fase.

Com relação aos custos, Machado e Lopes (2000) citam que, no setor florestal, a colheita e o transporte de madeira são as fases mais importantes economicamente em função da alta participação no custo final do produto e pelos riscos de perdas.

Neste trabalho, objetivou-se analisar as receitas e os custos obtidos para diferentes cenários de produtividade de madeira durante seis anos de investimento e obter o Valor Presente Líquido (VPL), a Taxa Interna de Retorno (TIR) e o Custo Médio de Produção (CMP) para cada cenário de produtividade da produção de madeira para celulose do programa de fomento no Estado do Espírito Santo.

\section{MATERIAL E MÉTODOS}

Essa pesquisa foi executada em uma propriedade rural participante do programa de fomento florestal do sul do estado do Espírito Santo, localizada no município de São José do Calçado. A coleta de dados para a implantação e manutenção do primeiro ano foi realizada de agosto de 2008 a dezembro de 2009. A partir do segundo ano, os dados de manutenção, colheita e transporte foram estimados conforme o fomento da região (Tabela 1).

A área plantada na propriedade foi de 17,02 hectares, no sistema manual, com uma inclinação média de $36,5 \%$. O plantio foi realizado em dezembro de 2008 e a previsão de colheita da madeira é esperada ao final do sexto ano. O espaçamento médio de plantio adotado foi de $3 \times 3$ metros, totalizando, aproximadamente, 1.111 plantas por hectare. A espécie plantada foi o híbrido Eucalyptus grandis x Eucalyptus urophylla produzida por propagação vegetativa (PEREIRA, 2010).

Para o cálculo de custos dos insumos (arames, grampos, mourões, estacas, fertilizantes, formicidas e herbicidas) utilizados na implantação e manutenção do plantio, primeiramente constatava-se a quantidade utilizada de cada produto e, posteriormente, verificava-se o preço de aquisição desses produtos pelo produtor pelas notas fiscais.

Cerne, Lavras, v. 17, n. 4, p. 473-479, out./dez. 2011
Os custos de implantação e manutenção do povoamento foram separados em custos do fomentado e custos subsidiados pela empresa. Os custos de colheita foram simulados em função das produtividades médias da região, considerando quatro cenários, sendo a produtividade mínima de $140 \mathrm{~m}^{3} / \mathrm{ha}, 180 \mathrm{~m}^{3} / \mathrm{ha}$, $220 \mathrm{~m}^{3} / \mathrm{ha}$ e a máxima de $250 \mathrm{~m}^{3} / \mathrm{ha}$. O gasto obtido com o transporte foi referente ao custo do frete para uma distância de $82 \mathrm{~km}$ da área de plantio até o pátio da empresa, considerando custo de $\mathrm{R} \$ 1,50 / \mathrm{km}$ rodado (mercado regional).

A viabilidade econômica do projeto foi analisada pelo método do valor presente líquido (VPL), taxa interna de retorno (TIR) e custo médio de produção (CMP) (REZENDE; OLIVEIRA, 2008).

De acordo com a teoria de análise de investimentos, pelo critério de VPL o projeto deve ser aceito quando seu valor for positivo, sendo mais atrativo o projeto quanto maior o seu valor. Em caso de ser negativo, o projeto será economicamente inviável.

$$
V P L=\sum_{j=0}^{n} R j(1+i)^{-j}-\sum_{j=0}^{n} C j(1+i)^{-j}
$$

em que: $R j=$ Receita no final do ano $j$, em R $\$ ; j=$ Custo no final do ano $j$, em R $\$ ; i=$ Taxa de desconto; $n=$ duração do projeto, em anos.

Foi utilizada uma taxa de juros anual de $8,75 \%$ (taxa SELIC vigente na época da realização da pesquisa) e o preço da madeira acertado no contrato no ano “zero" foi de R $\$ 67,16 / \mathrm{m}^{3}$. A TIR de um projeto é a taxa anual de retorno do capital investido, sendo o projeto economicamente viável, quando a TIR for maior do que a taxa de desconto considerada como referência, no caso a taxa SELIC (REZENDE; OLIVEIRA, 2008).

O Custo Médio da Produção (CMP) resulta da relação entre custo total atualizado $\left(\mathrm{CT}_{\mathrm{j}}\right)$ e a produção total equivalente $\left(\mathrm{QT}_{\mathrm{j}}\right)$. Quanto à seleção de projetos viáveis economicamente, será escolhido o que apresentar o menor CMP (REZENDE; OLIVEIRA, 2008).

$$
C M P=\frac{\sum_{j=0}^{n} C T_{j}}{\sum_{j=0}^{n} Q T_{j}}
$$

em que: $n=$ duração do projeto, em anos; $j=$ período de tempo em que os custos e as quantidades produzidas ocorreram. 
Tabela 1 - Descrição das operações florestais na propriedade localizada no município de São José do Calçado-ES.

Table 1 -Description of forest operation in the rural property located in São José do Calçado-ES.

\begin{tabular}{|c|c|}
\hline Operações Florestais & Descrição \\
\hline Roçada & $\begin{array}{l}\text { Processo de limpeza no terreno, no qual se retiram plantas indesejáveis da área utilizando-se de } \\
\text { foices. }\end{array}$ \\
\hline Capina química pré-plantio & $\begin{array}{l}\text { Procedimento em que se usam herbicidas para eliminar plantas indesejáveis. Feito de forma } \\
\text { manual com o pulverizador costal antes do plantio. }\end{array}$ \\
\hline Marcação e alinhamento & $\begin{array}{l}\text { Etapa de planejamento e demarcação das covas na área. Realizado de forma manual com o uso } \\
\text { de barbantes, trena e enxadão. }\end{array}$ \\
\hline Coveamento & $\begin{array}{l}\text { Procedimento de escavação do solo para preparo do plantio. Utiliza o enxadão como } \\
\text { ferramenta de trabalho (atividade realizada de forma manual). }\end{array}$ \\
\hline Adubação pré-plantio & $\begin{array}{l}\text { A aplicação de adubo conforme análise de solo na cova de plantio. Após depósito do adubo na } \\
\text { cova, este deve ser misturado manualmente ao solo. }\end{array}$ \\
\hline Enchimento de cova & Processo de preenchimento das covas com solo com o uso de enxada. \\
\hline $\begin{array}{l}\text { Combate e repasses às } \\
\text { formigas cortadeiras }\end{array}$ & Distribuição manual e de forma sistemática de formicidas abrangendo toda a área de plantio. \\
\hline Plantio e Replantio & $\begin{array}{l}\text { Processo de introdução das mudas nas covas. Esta operação é realizada de forma manual } \\
\text { com o uso de chucho. Procedimento de substituição das mudas mortas ou que não atingiram } \\
\text { desenvolvimento esperado. }\end{array}$ \\
\hline Coroamento & $\begin{array}{l}\text { Eliminação de invasoras envolta da muda (círculo). Atividade realizada de forma manual com } \\
\text { enxada (raio médio de } 60 \mathrm{~cm} \text { ). }\end{array}$ \\
\hline Capina química pós-plantio & $\begin{array}{l}\text { Procedimento em que se usam herbicidas para eliminar plantas indesejáveis. Feito de forma } \\
\text { manual com o pulverizador costal e adaptação de chapéu de napoleão no bico pulverizador, } \\
\text { feito depois do plantio. }\end{array}$ \\
\hline $\begin{array}{l}\text { Adubação de cobertura e de } \\
\text { manutenção de } 1 \text { ano }\end{array}$ & $\begin{array}{l}\text { Distribuição manual do adubo nas laterais da muda a lanço. O tipo e dosagem dos adubos } \\
\text { variam conforme resultado de análise de solo. }\end{array}$ \\
\hline Aplicação de calcário & $\begin{array}{l}\text { Distribuição a lanço de calcário, com a dosagem conforme resultado de análise de solo. Fonte } \\
\text { de cálcio e magnésio. }\end{array}$ \\
\hline Aceiro & $\begin{array}{l}\text { Raspagem de uma faixa nas margens das áreas plantadas (aproximadamente } 3 \text { metros de } \\
\text { largura) para maior proteção contra incêndios. Realizado com o uso de foice, enxada e rastelo. }\end{array}$ \\
\hline Colheita & $\begin{array}{l}\text { Conjunto de operações para derrubar e extrair a madeira até a margem da estrada. Envolve as } \\
\text { fases de derrubada, desgalhamento, traçamento, extração e empilhamento. }\end{array}$ \\
\hline Transporte & $\begin{array}{l}\text { Consiste na movimentação da madeira empilhada na margem da estrada ao pátio de transbordo } \\
\text { de madeira da empresa, via modal rodoviário. }\end{array}$ \\
\hline
\end{tabular}

Fonte: Elaborado pelos autores.

\section{RESULTADOS E DISCUSSÃO}

O custo de mão-de-obra e obrigações trabalhistas e sociais foi de $\mathrm{R} \$ 3,80$ a hora trabalhada, conforme detalhado em Pereira (2010), que considerou custos de um contrato temporário de trabalho e os coeficientes técnicos para cada atividade.

$\mathrm{Na}$ Tabela 2, indicam-se os custos aos quais o produtor incorre quando da realização do empreendimento florestal. De uma maneira geral, esses custos são os mesmos para as fases de implantação e manutenção em diferentes cenários de produtividade, porém os custos de colheita e transporte são diferentes para cada cenário.

Pelos resultados apresentados na Tabela 2, os custos de implantação e manutenção totalizaram R \$ 3.774,52/ha em seis anos de ciclo de produção, sendo que a maior parte desses custos é verificada no primeiro ano de investimento ( R \$ 2.884,99/ha), o que corresponde a 76,43\% do total dos custos no período.

$\mathrm{Na}$ Tabela 3, mostram-se os valores totais $\left(\mathrm{R} \$ / \mathrm{m}^{3}\right)$, aos quais o produtor incorre em despesas com colheita e

Cerne, Lavras, v. 17, n. 4, p. 473-479, out./dez. 2011 
Tabela 2 - Valores de custo (R\$/ha), capacidade operacional efetiva (COE em ha/h), com mão-de-obra até o sexto ano para a implantação e manutenção do povoamento florestal na propriedade rural localizada no município de São José do Calçado-ES.

Table 2 -Amounts funded by the producer $\left(R \$ h a^{-1}\right)$, effective operational capability (COE in ha $\left.h^{-1}\right)$ with labor until the sixth year for implementation and maintenance of the forest stand in a rural property in the municipality of São José do Calçado-ES.

\begin{tabular}{|c|c|c|c|c|c|c|c|c|c|}
\hline \multirow{2}{*}{ Atividades } & \multirow{2}{*}{ Fase } & \multirow{2}{*}{$\begin{array}{l}\mathrm{COE} \\
\mathrm{ha} / \mathrm{h}\end{array}$} & \multicolumn{7}{|c|}{ Anos } \\
\hline & & & 0 & 1 & 2 & 3 & 4 & 5 & 6 \\
\hline \multirow{8}{*}{$\begin{array}{l}\text { Atividades } \\
\text { prévias de } \\
\text { preparo da } \\
\text { área }\end{array}$} & Insumo (formicidas) & - & 13,77 & & & & & & \\
\hline & Combate inicial a formigas & 0,446 & 50,01 & & & & & & \\
\hline & $\begin{array}{l}\text { Construção de cercas (aquisição de material e } \\
\text { mão de obra) }\end{array}$ & - & 401,44 & & & & & & \\
\hline & Roçada pré-plantio & 0,037 & 103,52 & & & & & & \\
\hline & Transporte de mourões & - & 20,71 & & & & & & \\
\hline & Construção de estrada & - & 52,19 & & & & & & \\
\hline & Herbicida pré-plantio (aquisição do herbicida) & - & 52,30 & & & & & & \\
\hline & $\begin{array}{l}\text { Capina química pré-plantio (pulverizador } \\
\text { costal manual) }\end{array}$ & 0,043 & 88,92 & & & & & & \\
\hline \multirow{5}{*}{$\begin{array}{l}\text { Preparo de } \\
\text { solo }\end{array}$} & Coveamento & 0,019 & 201,05 & & & & & & \\
\hline & Alinhamento e marcação de covas & 0,019 & 196,69 & & & & & & \\
\hline & Insumo (adubo de cova) & - & 498,16 & & & & & & \\
\hline & Aplicação de adubo de cova & 0,085 & 44,86 & & & & & & \\
\hline & Enchimento de covas & 0,028 & 134,57 & & & & & & \\
\hline \multirow{5}{*}{ Plantio } & Insumo (mudas) & - & 375,33 & & & & & & \\
\hline & Transporte (mudas e água) & - & 24,23 & & & & & & \\
\hline & Plantio & 0,057 & 67,18 & & & & & & \\
\hline & Replantio & 0,344 & 11,04 & & & & & & \\
\hline & $\begin{array}{l}\text { Retirada das mudas dos tubetes e transporte } \\
\text { para cova }\end{array}$ & 0,335 & 11,35 & & & & & & \\
\hline \multirow{12}{*}{ Manutenção } & Coroamento & 0,039 & 97,87 & & & & & & \\
\hline & Insumos (formicidas) & - & 4,16 & 4,16 & 4,16 & 4,16 & 4,16 & 4,16 & 9,61 \\
\hline & Aplicação de formicidas & 0,367 & 7,76 & 10,35 & 10,35 & 10,35 & 10,35 & 10,35 & 10,35 \\
\hline & Insumo (adubo de cobertura) & - & 269,60 & & & & & & \\
\hline & Insumo (adubo de manutenção) & - & & 303,17 & & & & & \\
\hline & Insumo (calcário) & - & & 90,40 & & & & & \\
\hline & Transporte de adubo & 0,478 & 7,95 & 15,90 & & & & & \\
\hline & Aplicação de adubos & 0,063 & 63,84 & 127,68 & & & & & \\
\hline & Herbicida pós-plantio (aquisição do herbicida) & - & 41,84 & 41,84 & & & & & \\
\hline & Aplicação de herbicidas pós plantio & 0,060 & 44,65 & 44,65 & & & & & \\
\hline & Manutenção de aceiros & 0,164 & - & 23,23 & 23,23 & 23,23 & 23,23 & 23,23 & 23,23 \\
\hline & Manutenção de estradas* & 1,470 & & & & & & & 34,00 \\
\hline Total (R\$/ha) & - & & $2.884,99$ & 661,38 & 37,74 & 37,74 & 37,74 & 37,74 & 77,19 \\
\hline $\begin{array}{l}\text { Total Geral } \\
(\mathrm{R} \$ / \mathrm{ha})\end{array}$ & - & & & & & 774,52 & & & \\
\hline
\end{tabular}

Nota: $\mathrm{COE}=$ Capacidade Operacional Efetiva; $\mathrm{h}=$ hora

* O valor deste item foi calculado tomando-se por base o preço da hora do trator terceirizado (R\$50,00/ hora)

Fonte: Elaborado pelos autores.

Cerne, Lavras, v. 17, n. 4, p. 473-479, out./dez. 2011 
Tabela 3 - Valores dos Custos de produção (R\$/ha) e capacidade operacional efetiva (ha/h), com mão-de-obra no sexto ano para colheita e transporte do povoamento florestal na propriedade rural localizada no município de São José do Calçado-ES.

Table 3 - Production cost $\left(R \$ h a^{-1}\right)$, effective operational capability (COE in ha $\left.h^{-1}\right)$ with labor in the sixth year to harvest and transport in a rural property located in the municipality of São José do Calçado-ES.

\begin{tabular}{|c|c|c|c|c|c|c|}
\hline \multirow{2}{*}{ Atividades } & \multirow{2}{*}{ Fases } & \multirow{2}{*}{$\begin{array}{l}\text { Coeficiente técnico } \\
\left(\mathrm{R} \$ / \mathrm{m}^{3}\right)\end{array}$} & \multicolumn{4}{|c|}{ Cenários } \\
\hline & & & $140 \mathrm{~m}^{3} / \mathrm{ha}$ & $180 \mathrm{~m}^{3} / \mathrm{ha}$ & $220 \mathrm{~m}^{3} / \mathrm{ha}$ & $250 \mathrm{~m}^{3} / \mathrm{ha}$ \\
\hline \multirow{3}{*}{ Colheita } & Corte com motosserra & 4,69 & 656,60 & 844,20 & 1031,80 & 1172,50 \\
\hline & Extração por tombamento manual & 0,99 & 138,60 & 178,20 & 217,80 & 247,50 \\
\hline & Carregamento manual & 2,25 & 315,00 & 405,00 & 495,00 & 562,50 \\
\hline Transporte & Frete rodoviário & 13,30 & $1.722,00$ & $2.214,00$ & $2.706,00$ & $3.075,00$ \\
\hline Total (R $\$ /$ ha & & - & $6.606,72$ & $7.532,07$ & $8.341,27$ & $8.948,17$ \\
\hline
\end{tabular}

Nota: Os custos de colheita e transporte variaram conforme cada cenário de produtividade

Fonte: Elaborado pelos autores.

transporte. Os custos dessas atividades são diferentes para cada cenário de produtividade considerado.

O custo total para cada cenário de produtividade (Tabelas 2 e 3 ) foi de $\mathrm{R} \$ 10.381,24 /$ ha, $\mathrm{R} \$ 11.306,59 / \mathrm{ha}$, $\mathrm{R} \$ 12.115,79 /$ ha e $\mathrm{R} \$ 12.722,69 /$ ha, respectivamente, para $140,00 \mathrm{~m}^{3} / \mathrm{ha}, 180,00 \mathrm{~m}^{3} / \mathrm{ha}, 220,00 \mathrm{~m}^{3} /$ ha e de 250,00 $\mathrm{m}^{3} /$ ha. Os custos de colheita e transporte variaram com a produção, representando $63,64 \%, 66,62 \%, 68,85 \%$ e $70,33 \%$ dos custos totais de produção, para os mesmos cenários. Dentre os custos de colheita e transporte, o transporte foi a atividade que mais influenciou os custos de cada cenário (Tabela 3 ).

$\mathrm{Na}$ Tabela 4, indica-se o valor dos dispêndios que a empresa fomentadora incorre, na forma de insumos entregues na propriedade do produtor.

Tabela 4 - Insumos custeados pela empresa para a implantação e manutenção até o sexto ano do povoamento florestal.

Table 4-Subsidies provided by the company for installation and maintenance until the sixth year of forest stand

\begin{tabular}{lcc}
\hline Atividades & Insumo & Custo (R\$) \\
\hline $\begin{array}{l}\text { Atividades prévias } \\
\text { de preparo da área e }\end{array}$ & Adubo de cova & 498,16 \\
Preparo do solo & Formicidas & 17,93 \\
\hline Plantio & Mudas & 375,33 \\
\hline & Adubação de cobertura & 269,60 \\
Manutenção & Adubação de manutenção & 303,17 \\
& Calcário & 90,40 \\
& Formicidas & 30,41 \\
\hline Total (R $\$$ ha) & - & $1.585,00$ \\
\hline
\end{tabular}

Fonte: Elaborado pelos autores.
Analisando todas as etapas do empreendimento, o produtor incorre com a maior parte dos custos nas etapas de implantação e manutenção florestal $(58,01 \%)$, enquanto que a empresa de fomento responsabiliza-se por $41,99 \%$ dos custos.

Na Figura 1, indica-se o fluxo de caixa para os seis anos de investimento do empreendimento florestal.

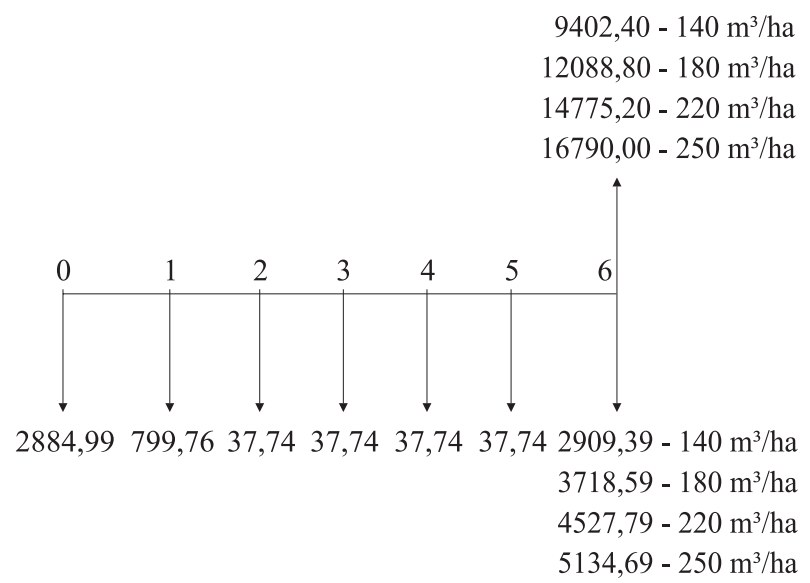

Fonte: Elaborado pelos autores.

Figura 1 - Fluxo de caixa para um horizonte de planejamento de seis anos em R \$/ha (os custos de implantação e manutenção não variam com a produtividade ("zero" a seis anos) e os custos de colheita e transporte e a receita variaram de acordo com os cenários de produtividade).

Figure 1 - Cash Flow for a planning horizon of six years in $R \$ h^{-1}$ (the cost of deployment and maintenance do not vary with productivity (zero to six years) and the costs of harvesting and transport and revenues vary according to the scenarios of productivity).

Cerne, Lavras, v. 17, n. 4, p. 473-479, out./dez. 2011 
Pelo fluxo de caixa (Figura 1) em todos os anos demandaram-se custos e a receita foi obtida apenas no ultimo ano do investimento. Os maiores custos são necessários no sexto ano, em razão dos custos de colheita e transporte que são diretamente proporcionais ao aumento do incremento anual de madeira (cenários de produtividade).

$\mathrm{Na}$ Figura 2, apresenta-se a relação do VPL encontrado para diferentes cenários de produtividade do povoamento florestal.

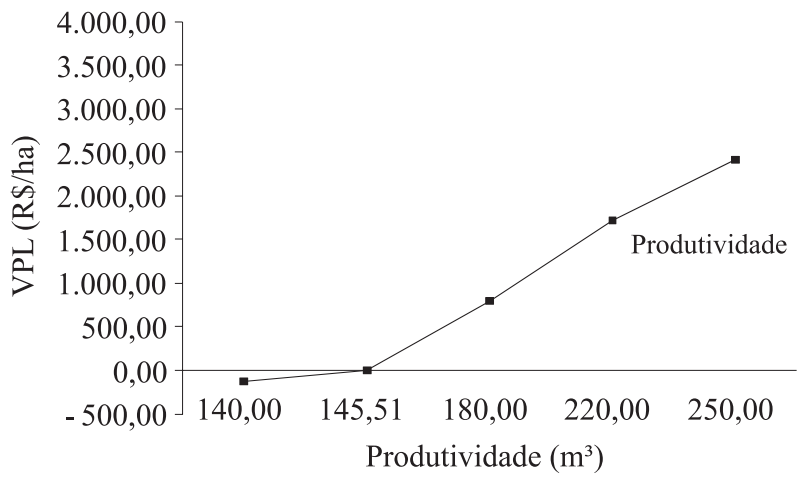

Fonte: Elaborado pelos autores.

Figura 2 - Relação do VPL com cenários alternativos de produtividades.

Figure 2 - Relation of VPL to the alternative scenarios of productivity.

O VPL representa o lucro líquido e descontado para um horizonte de seis anos. $\mathrm{O}$ empreendimento apresenta receitas equivalentes aos custos para uma produtividade de $145,51 \mathrm{~m}^{3} / \mathrm{ha}$, sendo, nessa produtividade um investimento de alto risco (Figura 2). Abaixo desse valor, o produtor terá prejuízos na atividade de fomento florestal com eucalipto para a produtividade mínima $\left(140,00 \mathrm{~m}^{3} / \mathrm{ha}\right)$ ele perderá $\mathrm{R} \$ 127,14 /$ ha. Para a máxima produtividade proposta $\left(250,00 \mathrm{~m}^{3} / \mathrm{ha}\right)$, obteve-se um VPL de R $\$ 2.412,14 / \mathrm{ha}$, sendo $202,97 \%$ e $40,27 \%$ maior do que o VPL para as produtividades de $180 \mathrm{~m}^{3} / \mathrm{ha} \mathrm{e} 220 \mathrm{~m}^{3} / \mathrm{ha}$, respectivamente.

Resende et al. (2004) encontraram VPL positivo efetivo a partir da produtividade de eucalipto de 133,60 $\mathrm{m}^{3} / \mathrm{ha}$, estando esse valor próximo ao encontrado neste trabalho, não havendo, portanto, perda de receita ao longo do tempo. Rezende et al. (2006), simulando uma variação de $\pm 20 \%$ na produtividade do plantio de eucalipto, constataram que a situação de maior produtividade foi mais atraente, com VPL 140,10\% maior para o cenário com 300 $\mathrm{mst} / \mathrm{ha}$ do que o cenário de $200 \mathrm{mst} / \mathrm{ha}$.

Cerne, Lavras, v. 17, n. 4, p. 473-479, out./dez. 2011
Na Tabela 5, indica-se a Taxa Interna de Retorno (TIR) e o Custo Médio de Produção (CMP), para os cenários de produtividade para a atividade de fomento florestal de eucalipto.

Tabela 5 - Cenários de produtividade para a atividade de fomento florestal com eucalipto, Taxa Interna de Retorno (TIR) e Custo Médio de Produção (CMP).

Table 5 - Productivity scenarios for the activity of eucalyptus forest development, Internal Rate of Return (TIR) and Average Cost of Production (CMP).

\begin{tabular}{lcccc}
\hline $\begin{array}{l}\text { Produtividade } \\
\left(\mathrm{m}^{3} / \mathrm{ha}\right)\end{array}$ & 140,00 & 180,00 & 220,00 & 250,00 \\
\hline $\mathrm{TIR}(\%)$ & 8,16 & 12,03 & 15,19 & 17,24 \\
$\mathrm{CMP}\left(\mathrm{R} \$ \mathrm{~m}^{3}\right)$ & 58,29 & 49,47 & 43,86 & 40,83 \\
\hline
\end{tabular}

Nota: taxa de juros anual de $8,75 \%$

Fonte: Elaborado pelos autores.

Para uma taxa anual de $8,75 \%$ ao ano, foi possível verificar que o empreendimento é viável para 180,00 $\mathrm{m}^{3} / \mathrm{ha}, 220,00 \mathrm{~m}^{3} / \mathrm{ha}$ e $250,00 \mathrm{~m}^{3} / \mathrm{ha}$ de produtividades, apresentando as respectivas TIR de $12,03 \%, 15,19 \%$ e $17,24 \%$. Assim, o cenário com $250 \mathrm{~m}^{3} /$ ha possui a maior TIR e é mais atraente por conseguir rentabilidade superior $97,03 \%$ à taxa de $8,75 \%$ considerada (Tabela 5 ). Rezende et al. (2006), simulando uma análise multivariada e considerando a distância de $100 \mathrm{~km}$ e preço da madeira de $\mathrm{R} \$ 100,00 / \mathrm{mst}$, encontraram a TIR de $28 \%, 33 \%$ e $37 \%$, respectivamente, para as produtividades de 200, 250 e 300 $\mathrm{mst} / \mathrm{ha}$, para a mesma taxa de $8,75 \%$.

Em relação ao CMP (Tabela 5), para a taxa de juros estimada, manteve-se a ordem de preferência dos projetos: em presença de maior produção, o projeto $250,00 \mathrm{~m}^{3} / \mathrm{ha}$ se mostrou o mais atraente $\left(40,83 \mathrm{R} \$ / \mathrm{m}^{3}\right)$ e, em presença de menor produção, o projeto 140,00 $\mathrm{m}^{3} /$ ha foi o menos atraente $\left(58,29 \mathrm{R} \$ / \mathrm{m}^{3}\right)$. Rezende et al. (2006), comentam que, além da taxa de juros, outros fatores podem influenciar a viabilidade econômica de projetos florestais, como, por exemplo: o preço da madeira, a produtividade dos projetos e os custos de produção.

Essa melhor viabilidade em função da maior produtividade comprova a necessidade de o produtor investir em tecnologia em seus povoamentos. O simples fato de plantar, sem a observância dos tratos culturais adequados pode acarretar prejuízos pela baixa produtividade do empreendimento. 


\section{CONCLUSÕES}

De acordo com os resultados obtidos, para as condições em que este estudo foi desenvolvido, concluise que:

- a receita bruta para cada cenário de produtividade foi de $\mathrm{R} \$ 9.402,40 / \mathrm{ha}$; $\mathrm{R} \$ 12.088,80 / \mathrm{ha}, \mathrm{R} \$ 14.775,20 / \mathrm{ha}$ e R $\$ 16.790,00 /$ ha, respectivamente, para $140 \mathrm{~m}^{3} / \mathrm{ha}, 180$ $\mathrm{m}^{3} / \mathrm{ha}, 220 \mathrm{~m}^{3} / \mathrm{ha}$ e $250 \mathrm{~m}^{3} / \mathrm{ha}$;

- na análise econômica do investimento florestal, sob a ótica do produtor fomentado, verifica-se que sua viabilidade ocorre a partir do nível de produtividade de $145,51 \mathrm{~m}^{3} / \mathrm{ha}$;

- o empreendimento não foi viável para a produtividade mínima de $140,00 \mathrm{~m}^{3} / \mathrm{ha}$ (VPL de -R\$ 127,14/ha, TIR de $8,16 \%$ e CMP de R $\$ 58,29 / \mathrm{m}^{3}$ ). Já, para os demais cenários, a análise econômica demonstrou que o empreendimento é viável, sendo mais atrativa a produtividade de $250,00 \mathrm{~m}^{3} / \mathrm{ha}$ por apresentar o maior VPL (R \$ 2.412,14/ha), maior TIR (17,24\%) e menor CMP $\left(\mathrm{R} \$ 40,83 / \mathrm{m}^{3}\right)$;

- uma forma de garantir melhor rentabilidade ao produtor florestal é incentivar a atividade por meio de políticas públicas que preconizem a adoção de menor taxa de juros, uma vez que o investimento é de longo prazo.

\section{AGRADECIMENTOS}

Ao laboratório de colheita, ergonomia e logística florestal (DEF-CCA-UFES) pela infraestrutura concedida para a execução do trabalho, ao Conselho Nacional de Desenvolvimento Científico e Tecnológico (CNPq), pela concessão de bolsas de Iniciação científica e de Produtividade em Pesquisa e à FAPES pelo apoio financeiro e concessão de bolsas de iniciação cientifica.

\section{REFERÊNCIAS}

MACHADO, C. C.; LOPES, E. S. Análise da influência do comprimento de toras de eucalipto na produtividade e custo da colheita e transporte florestal. Cerne, Lavras, v. 6, n. 2, p. 124-129, 2000.
PEREIRA, D. P. Análise técnica e de custos de povoamento de eucalipto sob preparo manual e mecanizado do solo em área declivosa no sul do Espírito Santo. 2010. 112 f. Dissertação (Mestrado em Ciências Florestais) Universidade Federal do Espírito Santo, Jerônimo Monteiro, 2010.

REZENDE, J. L. P.; OLIVEIRA, A. D. Análise econômica e social de projetos florestais. Viçosa, MG: UFV, 2008. $386 \mathrm{p}$.

REZENDE, J. L. P.; PÁDUA, C. T. J.; OLIVEIRA, A. D.; SCOLFORO, J. R. S. Análise econômica do fomento florestal com eucalipto no Estado de Minas Gerais. Cerne, Lavras, v. 12, n. 3, p. 221-231, jul./set. 2006.

RESENDE, R. R.; VALE, A. B. do; SOARES, T. S.; SILVA, M. L. da; COUTO, L.; VALE, R. S. do. Emprego de um modelo de crescimento e produção para determinação da rotação em povoamentos de eucalipto. Revista Árvore, Viçosa, v. 28, n. 2, p. 219-225, 2004.

SILVA, K. R.; MINETTI, L. J.; FIEDLER, N. C.; VENTUROLI, F.; MACHADO, E. G. B.; SOUZA, A. P. S. Custos e rendimentos operacionais de um plantio de eucalipto em região de cerrado. Revista Árvore, Viçosa, v. 28, n. 3, p. 361-366, 2004.

SIQUEIRA, J. D. P.; LISBOA, R. S.; FERREIRA, A. M.; SOUZA, M. F. R.; ARAÚJO, E.; LISBOA JÚNIOR, L.; SIQUEIRA, M. M. Estudo ambiental para os programas de fomento florestal da Aracruz Celulose S. A. e extensão florestal do Governo do Estado do Espírito Santo.

Revista Floresta, Curitiba, p. 3-67, nov. 2004. Edição especial.

SOARES, N. S.; SILVA, F. L.; SILVA, M. L.; LÍRIO, V. S. Viabilidade da implantação de um contrato de comercialização futura da madeira de reflorestamento no Brasil. Revista Árvore, Viçosa, v. 31, n. 2, p. 331-336, abr. 2007.

Cerne, Lavras, v. 17, n. 4, p. 473-479, out./dez. 2011 
